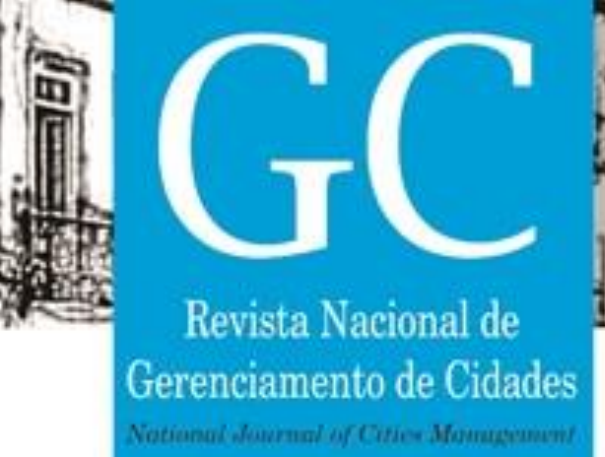

\title{
Antes das vilas: a paisagem natural de Presidente Prudente
}

Before the villages: the natural landscape of Presidente Prudente

Antes de las villas: el paisaje natural de Presidente Prudente

Beatriz Emboaba da Costa

Mestranda do PPGARQ, FAAC, UNESP Campus Bauru/SP

beatriz.emboaba@gmail.com

Nilson Ghirardello

Professor Assistente Doutor do PPGARQ, FAAC, UNESP Campus Bauru/SP

nghir@faac.unesp.br 


\section{RESUMO}

Presidente Prudente localiza-se na região tratada durante o século XIX como "Vale do Paranapanema", sendo que após a implantação da ferrovia passou a denominar-se mais precisamente "Alta Sorocabana". A ocupação urbana se deu a partir de 1917 e a inauguração da estação ocorreu dois anos depois, modificando a paisagem natural de forma drástica. Os trilhos passaram pelo espigão que divide a Bacia Hidrográfica do Rio Santo Anastácio e Rio do Peixe, cindindo em duas a área onde se formaria a futura cidade. A mata nativa foi substituída pelo traçado da Vila Goulart e em poucos anos outros loteamentos surgiram como Vila Nova e Vila Marcondes. De forma semelhante à maioria das cidades paulistas do período, o transporte ferroviário foi o principal agente de modificação da paisagem prudentina, secundado pelas atividades econômicas iniciadas pela extração da madeira e posteriormente o cultivo do café. O foco desse artigo é a descrição e análise da paisagem natural do sitio onde se implantou a cidade de Presidente Prudente até 1919, averiguado a partir de estudos acadêmicos como teses de doutorado e livros de memórias de engenheiros, agrimensores e do Coronel Goulart, um dos primeiros chefes políticos da zona.

Palavras-chave: Ferrovia Sorocabana, Presidente Prudente, Paisagem Natural;

\section{SUMMARY}

Presidente Prudente is located in the region treated during the nineteenth century as "Vale do Paranapanema", and after the implantation of the railroad was renamed "Alta Sorocabana". The urban occupation took place from 1917 and the inauguration of the station happened two years later, modifying the natural landscape of drastic form. The rails passed through the spigot that divides the River Basin of "Santo Anastácio" and River Basin of "Peixe", dividing in two the area where the future city would be formed. The native forest was replaced by the layout of the Vila Goulart and in a few years other allotments emerged as Vila Nova and Vila Marcondes. Similar to most of the cities of São Paulo during the period, railroad transportation was the main agent for the modification of the "prudentina" landscape, supported by the economic activities initiated by the extraction of wood and later the cultivation of coffee. The focus of this article is the description and analysis of the natural landscape of the site where the city of Presidente Prudente was implanted until 1919, ascertained from academic studies such as doctoral dissertations and memoirs of engineers, surveyors and Colonel Goulart, one of the first political leaders of the zone.

Key Words: Sorocabana Railway, Presidente Prudente, Natural Landscape;

\section{RESUMEN}

El presidente Prudente se localiza en la región tratada durante el siglo XIX como "Vale do Paranapanema", siendo que tras la implantación del ferrocarril pasó a denominarse más precisamente "Alta Sorocabana". La ocupación urbana se dio a partir de 1917 y la inauguración de la estación ocurrió dos años después, modificando el paisaje natural de forma drástica. Los carriles pasaron por la espiga que divide la Cuenca Hidrográfica del Río Santo Anastácio y Río del Peixe, escindiendo en dos el área donde se formaría la futura ciudad. La mata nativa fue sustituida por el trazado de la Vila Goulart y en pocos años otros loteamientos surgieron como Vila Nova y Vila Marcondes. De forma similar a la mayoría de las ciudades paulistas del período, el transporte ferroviario fue el principal agente de modificación del paisaje prudentina, secundado por las actividades económicas iniciadas por la extracción de la madera y posteriormente el cultivo del café. El foco de este artículo es la descripción y análisis del paisaje natural del sitio donde se implantó la ciudad de Presidente Prudente hasta 1919, averiguado a partir de estudios académicos como tesis de doctorado y libros de memorias de ingenieros, agrimensores y del Coronel Goulart, los primeros jefes políticos de la zona.

Palabras Claves: Ferrocarril Sorocabana, Presidente Prudente, Paisaje Natural; 


\section{INTRODUÇÃO}

O presente artigo faz parte do projeto de mestrado "Entre vilas: primórdio urbano de Presidente Prudente" FAAC-UNESP Bauru que abrange a formação urbana prudentina desde o final do século XIX até a década de 1930, final da Velha República, relacionando elementos urbanos com fatores econômicos, sociais e políticos. Nesse estudo será demonstrado um resultado parcial, com foco na paisagem natural de Presidente Prudente no período do final do século XIX até 1919, destacando pontos essenciais na modificação da paisagem, bem como de grande parcela das cidades paulistas do período, como a implantação da ferrovia, a extração da madeira, o cultivo do café e pontos específicos presentes na zona urbana prudentina como o surgimento da Vila Goulart, Vila Nova e Vila Marcondes.

Presidente Prudente é uma cidade paulista que está à $558 \mathrm{~km}$ da capital, a região em que está situada possuiu denominações distintas com o passar do tempo, como "Vale do Paranapanema ou Sertão do Paranapanema" (GIOVANETTI, 1943; ABREU, 1972) e "Alta Sorocabana", respectivamente nos séculos XIX e $\mathrm{XX}$, o primeiro termo faz referência ao rio elemento natural que localizava a zona e o segundo à estrada de ferro que permitiu a ocupação produtiva capitalista da região.

O desenvolvimento do transporte ferroviário no estado de São Paulo não pode ser analisado sem relacionálo com o cultivo do café, Matos (1981) denomina essa relação como "binômio café-ferrovia", um dos principais fatores de modificação da paisagem paulista nos séculos XIX e XX. A ferrovia e a produção cafeeira, ainda, "deslocam" a "boca do sertão" com o passar das décadas, o que marcou a divisão territorial do estado de forma relevante. É fato que durante o período áureo de atividade do transporte ferroviário as regiões eram popularmente e oficialmente conhecidas pelo nome das estradas de ferro (MATOS, 1981). Isso foi tão relevante que Millet (1938) chegou a propor a divisão territorial do Estado de São Paulo utilizando-se a denominação das companhias (Figura 1). Quatro ferrovias foram implantadas, ou expandidas, em espigões no planalto: Estrada de Ferro Araraquarense, Noroeste, Companhia Paulista e Sorocabana, tendo as denominações populares de Alta Araraquarense, Noroeste, Alta Paulista e Alta Sorocabana, como forma de distingui-las de seu trecho inicial, com exceção da Noroeste que havia nascido em Bauru, centro do estado de São Paulo (LEITE, 1972; GHIRARDELLO, 2002).

Na região de Presidente Prudente a estrada de ferro implantada foi a Sorocabana, tendo a estação prudentina sido inaugurada em 1919, como se tratava de uma extensão da companhia sobre zonas novas a região passou a ser denominada Alta Sorocabana (MILLET, 1938; LEITE, 1972; ABREU, 1972; MATOS, 1981). Durante décadas a cidade foi conhecida como a "Capital da Alta Sorocabana” (LEITE, 1972).

Atualmente uma das nomenclaturas oficiais da região é Região Administrativa de Presidente Prudente ou Região de Governo de Presidente Prudente (INSTITUTO GEOGRÁFICO E CARTOGRÁFICO, 2014). Nota-se que a cidade manteve o prestígio regional pois no cinquentenário de sua fundação era chamada de "Capital da Alta Sorocabana" (LEITE, 1972) e no centenário é oficialmente a sede da região administrativa. 


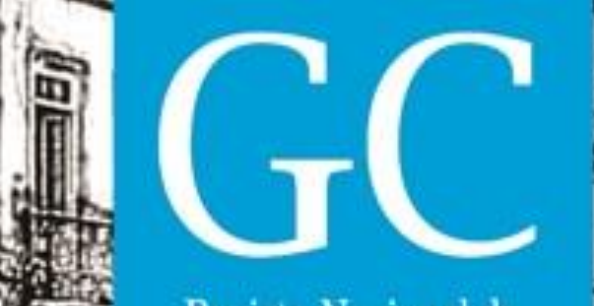

Revista Nacional de

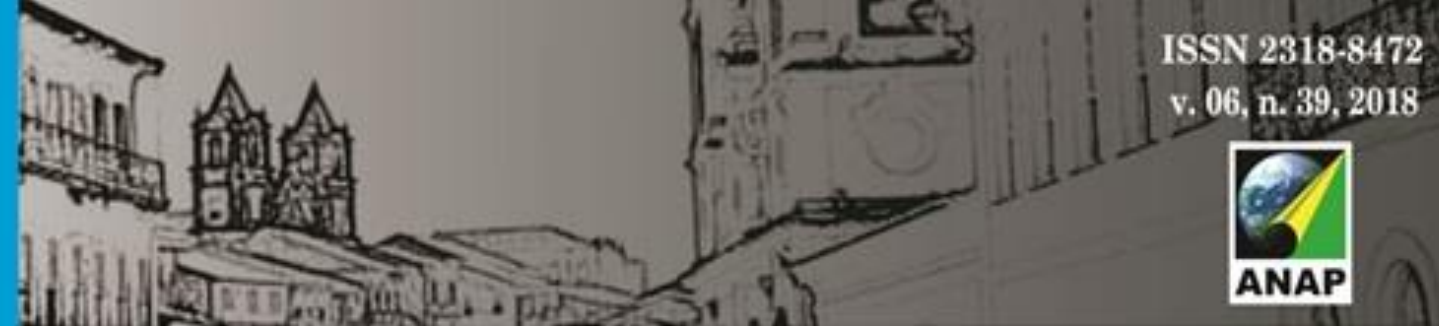

Gerenciamento de Cidades

Nas duas cidades acima percebe-se que além de similaridades na gênese da paisagem urbana, há pontos em comum na paisagem natural. Besse (2014) escreve que a paisagem também pode ser "uma representação cultural [...] como um território produzido pelas sociedades na sua história" (BESSE, 2014, p.3), dessa forma, os indígenas que habitavam essas regiões antes da "ocupação oficial do estado" também faziam parte da paisagem. No caso de Presidente Prudente "pertenciam ao grupo Guarani, também designados Cainguá ou Caiuá, além dos Tupiniquim, Xavante e Caigang, estes últimos também chamados de "Coroados" (ABREU, 1972, p.15) e também encontrados em Bauru (GHIRARDELLO, 2002, p.43).

Expandindo o conceito de Paisagem, utiliza-se nesse texto a definição de Besse (2014) da Paisagem como "um texto a ser decifrado [...] como um pensamento oculto a ser achado por trás dos objetos" (BESSE, 2014, p.21) e que não deve ser vista apenas como "o lugar presente, mas como local de memória" (BESSE, 2014 apud LOWENTHAL, 2008, p.14). A partir desse conceito que a pesquisa de mestrado e esse artigo se apóiam, no sentido de decifrar a paisagem natural de Presidente Prudente reconstituindo dados iconográficos, cartográficos e textos provenientes da memória de personagens influentes no primórdio urbano.

A fotografia de Presidente Prudente presente na Figura 2 é semelhante a delimitação da área urbana de 1934, sendo a Planta da cidade de 1934 utilizada como base para a reconstituição cartográfica desse estudo e da dissertação de mestrado, e uma das formas de reforçar os resultados dessa reconstituição é cruzandose informações de mais de uma fonte, como por exemplo a planta de Presidente Prudente de 1934 e a fotografia da década de 30 (Figura 2).

\section{OBJETIVO}

O objetivo do artigo é comparar duas visões sobre a paisagem natural de Presidente Prudente do final do século XIX até 1919, a primeira visão é acadêmica com base na tese de doutorado de Abreu (1972) e dissertação de mestrado de Ikuta (2003), Leite (1972), publicações de Sudo (1976; 1996), Pedro Miyasaki (2014) e a segunda visão é o resultado da descrição da paisagem de habitantes locais como as do Coronel Francisco de Paula Goulart (1965), João Carlos Fairbanks (1965).Além de mostrar como uma porção de cidades paulistas tiveram suas paisagens modificadas de forma drástica e semelhante tomando-se por base o conceito de Paisagem como local de memória e local para ser decifrado utilizado por Besse (2014).

\section{METODOLOGIA}

O conteúdo explanado faz parte do resultado parcial do projeto de mestrado e está inserido no capítulo dois do mesmo. Consequentemente a metodologia do artigo é a mesma do projeto que consiste na pesquisa (iniciada em 2016), estudo e análise do material iconográfico, cartográfico e bibliográfico a fim de desenvolver material textual e reconstituir o material cartográfico. No presente artigo expõe-se parte do material desenvolvido pelos autores com a modificação da paisagem prudentina, demonstrando as diferenças entre a paisagem natural e as primeiras transformações de setembro de 1917 até 1919 . Os principais autores utilizados como referência são Abreu (1972), Sudo $(1976,1996)$ e Ikuta (2003), além da publicação de Goulart (1965) denominada "Bandeirante do século XX" com narrativas importantes do Coronel Francisco de Paula Goulart e João Carlos Fairbanks (engenheiro da E. F. Sorocabana que atuou na 


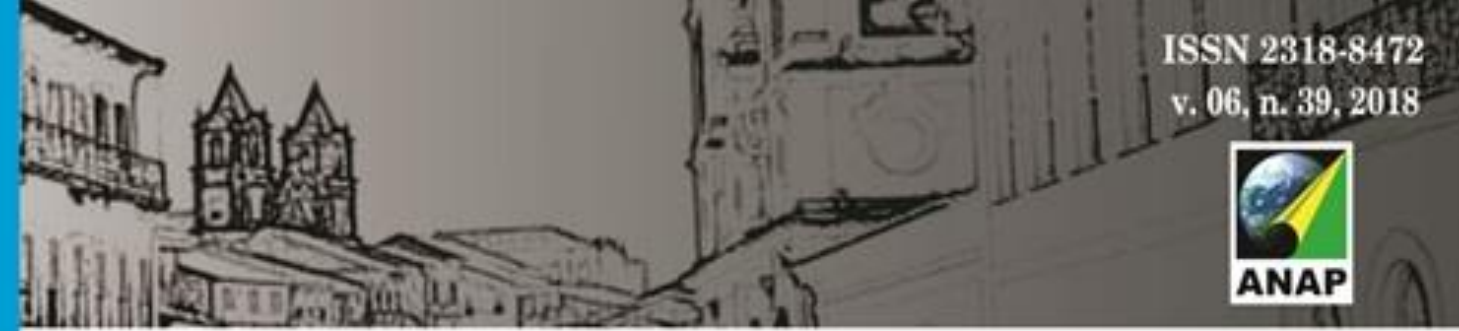

Gerenciamento de Cidades

Figura 4 - Paisagem Natural anterior a ocupação urbana

Paisagem Natural anterior a ocupação urbana

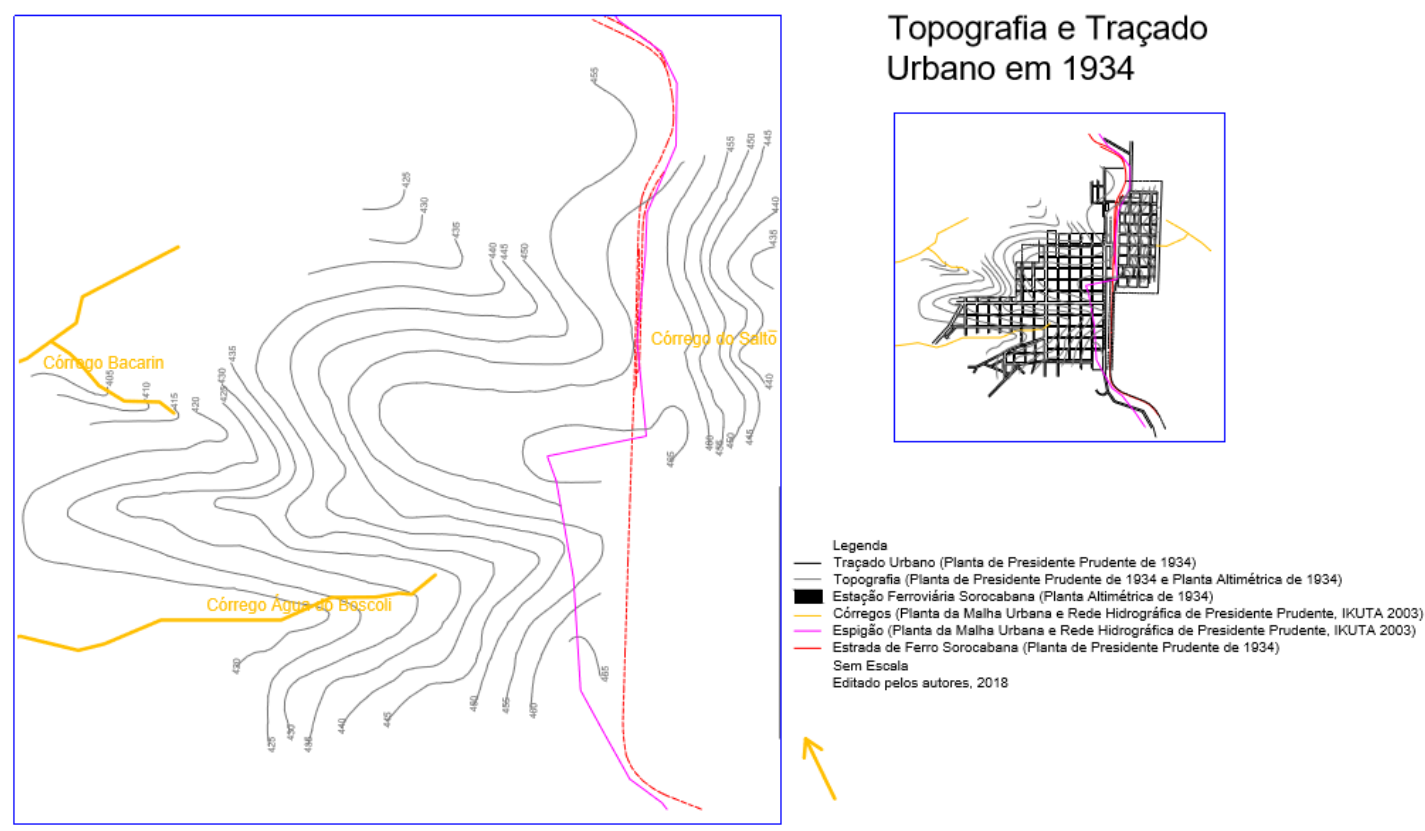

Fonte: Ikuta (2003); Arquivo Público do Estado de São Paulo; Elaborada pelos autores (2018).

Segundo Sudo (1976) "o sítio urbano de Presidente Prudente corresponde a um espigão geral mais elevado delineado por um conjunto de pequenos interflúvios" (SUDO, 1976, p.63). O lado leste (Vila Marcondes) tem uma declividade maior "perfil mais convexo", enquanto a porção oeste (Centro - antiga Vila Goulart e Vila Nova) tem "perfis convexos mais alongados, formando interflúvios mais suaves" (SUDO, 1976, p.64). Leal e Sudo (1996) escrevem sobre o solo do sítio: predomina "o solo Podzólico Vermelho Escuro na bacia do Córrego do Veado-Limoeiro e nas cabeceiras dos Córregos Gascata-Gramado e do Cedro-Botafogo predomina o Litossolo, seguido do Podzólico" (SUDO; LEAL, 1996, p.1).

Pedro Miyasaki (2014) utiliza-se dos termos de Ross e Moroz (1996, p.50) para definir a localização de Presidente Prudente, ou seja, o município está na Bacia Sedimentar do Paraná e no Planalto Ocidental Paulista. Também afirma que a cidade apresenta "um histórico de apropriação e ocupação urbana, que demonstra como os eixos de expansão territorial estão atrelados às características socioambientais" (PEDRO MIASAKI, 2014, p.29).

Assim como nas outras cidades paulistas, Presidente Prudente teve como primeiro ciclo econômico a extração da madeira, fato lógico pois a área era coberta por "mata" que foi substituída pelos cafezais, entretanto o plantio e comercialização demoravam alguns anos e durante esse período a extração da madeira foi essencial para o desenvolvimento econômico prudentino e de outras cidades da Alta Sorocabana que se formaram a partir da Estrada de Ferro ou concomitantemente (ABREU, 1972; MATOS, 1981). A madeira retirada, além de "limpar" o terreno para o plantio do café gerava parte da renda para 


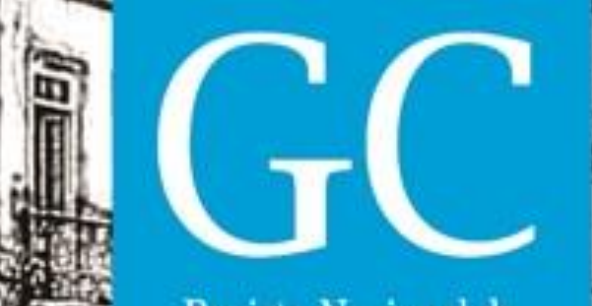

Revista Nacional de

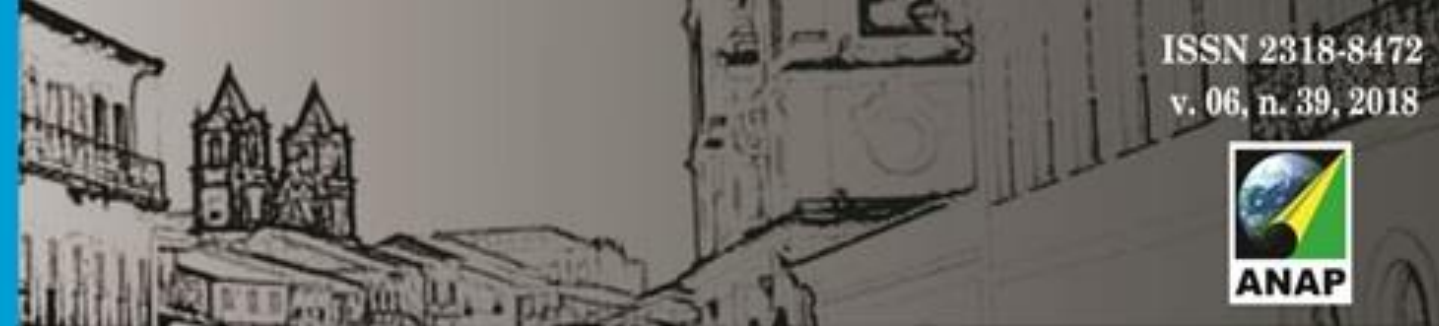

Gerenciamento de Cidades

subsidiar as plantações. A madeira era um produto muito procurado e de valor, aquela considerada "de lei" era utilizada para mobiliário e construção civil e a de "segunda" para lenha dos fogões das moradias e para queima nas locomotivas.

Antes desse ciclo econômico já existia uma "fase econômica", mas em escala menor e sem impactar de forma brusca a paisagem natural da região, segundo Leite (1972) a "fase do pastoreio" ocorreu até o fim da primeira guerra mundial "com criação de gado nas bordas da mata e do cerradão, aproveitando assim as gramíneas dos campos sujos" e plantação de milho (LEITE,1972, p.60) próximo de onde atualmente está localizada a cidade de Indiana. O autor finaliza a descrição dessa fase econômica como "apesar de economicamente inexpressiva, esta veio oferecer condições ao estabelecimento do colono agricultor na década seguinte" (LEITE, 1972, p.61).

A retirada da cobertura vegetal é um dos aspectos mais visíveis da modificação da paisagem natural na formação das cidades e considerado como a primeira fase econômica, Leite (1972) aponta "o pioneiro já devastou a vegetação, deixando desnudos os espigões" (LEITE, 1972, p.20). E completa: a vegetação nativa é um "vasto manto arbóreo [...] todo o Sudoeste Bandeirante era revestido por uma Floresta-PluvialTropical" (LEITE, 1972, p.26). A madeira foi um produto "desaparecido que deixou marcas na paisagem natural" e a Estrada de Ferro Sorocabana escoava a matéria-prima para capital, "as serrarias [...] transformavam os troncos de peroba, marfim, ipê, jatobá em táboas e vigas" e uma parte desse "produto" como a peroba era utilizada para construção dos primeiros edifícios urbanos e rurais (LEITE, 1972, p.62).

João Carlos Fairbanks (engenheiro da Ferrovia Sorocabana) chegou nas terras onde atualmente encontra-se Presidente Prudente em 12 de setembro de 1917 e descreve a paisagem como "inteiriço bloco de belíssima vestimenta de floresta virgem, com exceção interruptora do trecho campesino de Indiana" (FAIRBANKS, 1965, p.8).

A data de fundação da cidade foi considerada dois dias depois da chegada de Fairbanks e do Coronel Francisco de Paula Goulart, dia 14 de setembro de 1917, já que nesse dia teve início "a locação, em plena mata virgem do eixo" da atual Avenida Washington Luiz (FAIRBANKS, 1965, p.11), na planta de 1919 a Avenida recebeu o nome de Rio Branco e faz parte da primeira vila prudentina, a Vila Goulart (Figura 5).

A cidade teve seu núcleo urbano formado a partir do loteamento de partes de duas fazendas: Pirapó-Santo Anastácio e Montalvão, respectivamente formaram as Vila Goulart (Figura 5) e Vila Nova (ambas fundadas pelo Coronel Francisco de Paula Goulart) e a Vila Marcondes fundada pelo Coronel José Soares Marcondes, formando uma dualidade urbana que era fielmente refletida na política e na economia da cidade (ABREU, 1972).

A localização da Vila Goulart, na frente da futura estação da Ferrovia Sorocabana, inaugurada dois anos depois (Figura 5) possuiu relação direta com a estação, a esplanada e os trilhos da ferrovia que seriam implantados no espigão. Fairbanks narra detalhes do alinhamento dos quarteirões que compõe a vila: "teve início em novembro de 1918 sendo que primeiramente houve "mister" derrubar-se a espessa floresta e plantou-se a área, pois não havia plantação alguma" (FAIRBANKS, 1965, p.11). Neste momento a paisagem natural de Presidente Prudente começa a sofrer alterações significativas e o traçado urbano que se mantém até os dias atuais substitui a mata virgem.

Nota-se pelas curvas de nível (Figura 5) que essa área tem declividade mais suave do que a "do outro lado da linha", esse fato também foi importante, influenciando a direção da expansão urbana, porém, no início 


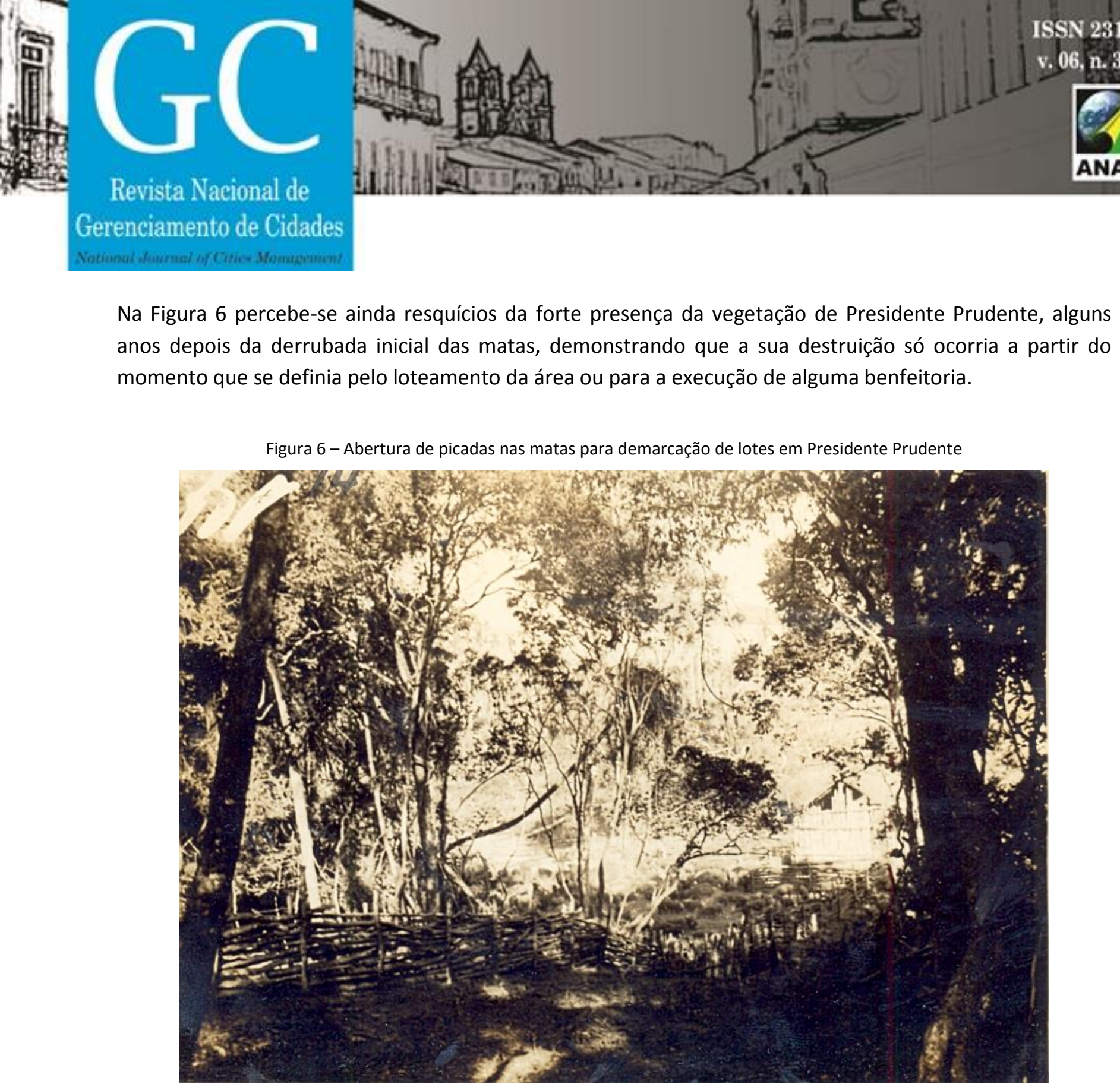

Fonte: Arquivo Museu Municipal Antônio Sandoval Netto de Presidente Prudente

Em outras imagens pesquisadas pelos autores e também a partir dos estudos bibliográficos é perceptível verificar que a infraestrutura urbana não foi implantada na cidade durante a década de 1920, esse processo ocorrerá apenas a partir dos anos 30. As ruas prudentinas não possuíam pavimentação, mesmo na área considerada nobre e "privilegiada" situada na frente da estação.

O posicionamento da Sorocabana influenciou as primeiras modificações da paisagem natural e durante anos a estação foi o "cartão postal" da cidade, fazendo com que as áreas ao seu redor fossem disputadas pelo incipiente mercado imobiliário. Devido a tais interesses existia uma preocupação constante do poder público, dominado pelos proprietários e loteadores das vilas, em mantê-las com uma aparência mais organizada e apresentável possível. Certamente será o espaço dos primeiros investimentos públicos que ocorrerão apenas nos anos seguintes, fora de nosso período de estudo. 


\section{CONCLUSÃO}

A partir das referências técnicas e dos relatos de personagens essenciais que atuaram na modificação da paisagem natural e formação da paisagem urbana é possível relacionar o conceito de Paisagem de Besse (2014) como local de memória e o esforço de redescobrir a paisagem presente na cidade no final do século XIX e primeiras décadas do século XX. Besse (2014) cita que a paisagem é "uma escrita na superfície da terra, produto [...] das atividades humanas" (BESSE, 2014, p.28). Presidente Prudente teve o núcleo urbano formado em função da estrada de ferro Sorocabana (no espigão que divide duas bacias hidrográficas), situação diferente de outras cidades paulistas do século XIX, como Bauru, que surgiu próximo aos cursos d'água. A expansão prudentina aconteceu na zona que em o relevo era mais suave e esse fato demonstra como a consolidação da paisagem urbana depende de fatores da paisagem natural, como a topografia e a presença de cursos d'água nas imediações. Porém é preciso destacar que o principal elemento influenciador da paisagem natural foi a estação da Estrada de Ferro Sorocabana, bem como o conjunto de sua esplanada, que determinou o primeiro traçado da cidade, as primeiras vilas e durante anos valorizou a área que estava "em sua frente" e desvalorizou a que estava em suas "costas". Sua existência é tão significativa e permanente que os trilhos da Sorocabana estão presentes na paisagem natural e na urbana durante os cem anos de Presidente Prudente e influenciaram de forma permanente a expansão urbana em todo século XX.

\section{REFERÊNCIAS}

Acervo do Museu Municipal Antônio Sandoval Netto de Presidente Prudente

Arquivo Público do Estado de São Paulo - Memória Pública, Planta da Cidade de Presidente Prudente, 1934

ABREU, Dióres Santos - Formação histórica de uma cidade pioneira paulista: Presidente Prudente. Faculdade de Filosofia, Ciências e Letras de Presidente Prudente, 1972

BESSE, Jean-Marc. $\boldsymbol{O}$ gosto do mundo: exercícios de paisagem. Rio de Janeiro: EdUERJ, 2014.

FAIRBANKS, João Carlos. Os primórdios da região de Alta Sorocabana. In: GOULART, Francisco de Paula - Bandeirante do século XX Fundação de Presidente Prudente narrada pelo Fundados 1917-1967, 1965

GHIRARDELLO, Nilson. À beira da linha: formações urbanas da Noroeste Paulista /Nilson Ghirardello. -São Paulo: Ed. da UNESP, 2002. 235 p.

GHIRARDELLO, Nilson. A formação dos patrimônios religiosos no processo de expansão urbana paulista (1850-1900) /Nilson Ghirardello. - São Paulo: Ed. da UNESP, 2010264 p.: il.

GIOVANETTI, Bruno. Esboço Histórico da Alta Sorocabana. São Paulo, Empresa Gráfica da Revista dos Tribunais Ltds, s.d. 1943

GOULART, Francisco de Paula - Bandeirante do século XX - Fundação de Presidente Prudente narrada pelo Fundados 1917-1967, 1965

LEITE, José Ferrari - A Alta Sorocabana e a região polarizada de Presidente Prudente. Tese de doutoramento apresentada a Cadeia de Geografia Regional da Faculdade de Filosofia, Ciências e Letras de Presidente Prudente, 1972 


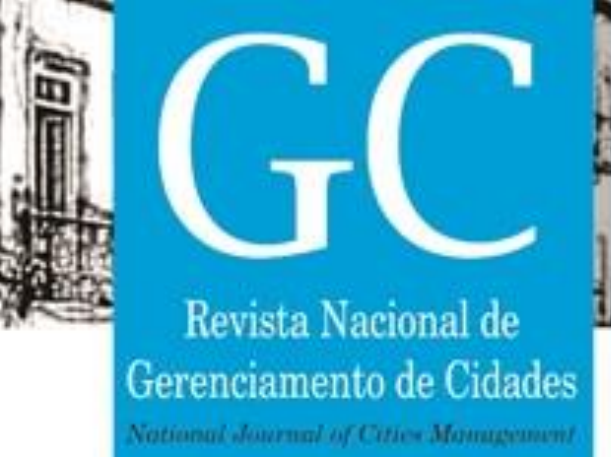

INSTITUto GEOgRÁfico e CARTOGRÁFICO. Mapa das Regiões Administrativas de São Paulo. 2016

IKUTA, Flávia Akemi. As cidades e as águas: a expansão territorial urbana e a ocupação dos fundos de vales em Presidente Prudente - SP, 2003

MATOS, Odilon Nogueira de. 1976- Café e Ferrovia: A evolução ferroviária de São Paulo e o desenvolvimento da cultura cafeeira / 3 ed. rev. São Paulo: Arquivo do Estado, 1981.

PEDRO MIYASAKI, Leda Correa. Dinâmicas de Apropriação e Ocupação em Diferentes Formas de Relevo: análise de impactos e da vulnerabilidade nas cidades de Presidente Prudente/SP e Marília/SP, 2014.

PRESIDENTE PRUDENTE, Base Cartográfica do Plano de Drenagem Urbana, 2017

SUDO, Hideo. Considerações em torno de algumas correlações fisiográficas do sistema urbano-industrial de Presidente Prudente. Boletim do Departamento de Geografia no7, FFCL, Presidente Prudente, SP, 1976.

SUDO, Hideo; LEAL, Antônio Cesar. Aspectos geomorfológicos e impactos ambientais da ocupação dos fundos de vales em Presidente Prudente, SP, 1996. 